\title{
In vivo insulin action and muscle glycogen synthase activity in Type 2 (non-insulin-dependent) diabetes mellitus: effects of diet treatment
}

\author{
J.F. Bak ${ }^{1}$, N. Møller ${ }^{2}$, O. Schmitz ${ }^{2}$, A.Saaek ${ }^{1}$ and O.Pedersen ${ }^{3}$ \\ ${ }^{1}$ Medical Endocrinological Department C, Aarhus Amtssygehus, ${ }^{2}$ Second University Clinic of Internal Medicine, \\ Aarhus Kommunehospital, Aarhus, and ${ }^{3}$ Steno Diabetes Center, Copenhagen, Denmark
}

\begin{abstract}
Summary. Insulin resistant glucose metabolism is a key element in the pathogenesis of Type 2 (non-insulin-dependent) diabetes mellitus. Insulin resistance may be of both primary (genetic) and secondary (metabolic) origin. Before and after diet-induced improvement of glycaemic control seven obese patients with newly-diagnosed Type 2 diabetes were studied with the euglycaemic clamp technique in combination with indirect calorimetry and forearm glucose balance. Muscle biopsies were obtained in the basal state and again after $3 \mathrm{~h}$ of hyperinsulinaemia $(200 \mathrm{mU} / 1)$ for studies of insulin receptor and glycogen synthase activities. Similar studies were performed in seven matched control subjects. Insulin-stimulated glucose utilization improved from $110 \pm 11$ to $183 \pm 23 \mathrm{mg} \cdot \mathrm{m}^{-2} \cdot \mathrm{min}^{-1} \quad(p<0.03)$; control subjects: $219 \pm$ $23 \mathrm{mg} \cdot \mathrm{m}^{-2} \cdot \min ^{-1}$ ( $p=$ NS, vs post-diet Type 2 diabetes). Nonoxidative glucose disposal increased from $74 \pm 17$ to $138 \pm$ $19 \mathrm{mg} \cdot \mathrm{m}^{-2} \cdot \mathrm{min}^{-1}(p<0.03)$, control subjects: $159 \pm 22 \mathrm{mg}$. $\mathrm{m}^{-2} \cdot \min ^{-1}$ ( $p=\mathrm{NS}$, vs post-diet Type 2 diabetic patients). Forearm blood glucose uptake during hyperinsulinaemia increased from $1.58 \pm 0.54$ to $3.35 \pm 0.23 \mu \mathrm{mol} \cdot \mathrm{l}^{-1} \cdot \mathrm{min}^{-1}$ $(p<0.05)$, control subjects: $2.99 \pm 0.86 \mu \mathrm{mol} \cdot \mathrm{l}^{-1} \cdot \mathrm{min}^{-1}$
\end{abstract}

( $p=$ NS, vs post-diet Type 2 diabetes). After diet therapy the increase in insulin sensitivity correlated with reductions in fasting plasma glucose levels $(r=0.97, p<0.001)$, reductions in serum fructosamine $(r=0.77, p<0.05)$, and weight loss $(r=0.78, p<0.05)$. Values of muscle glycogen synthase sensitivity to glucose 6-phosphate ( $A_{0.5}$ for glucose 6-phosphate) were similar in the basal state. However, insulin stimulation of glycogen synthase was more pronounced after diet treatment $\left(A_{0.5}: 0.43 \pm 0.06\right.$ (before) vs $0.30 \pm 0.04 \mathrm{mmol} / \mathrm{l}$ (after); $p<0.03$; control subjects: $0.22 \pm 0.03 \mathrm{mmol} / \mathrm{l})$. Muscle insulin receptor binding and kinase activity were similar before and after diet treatment and comparable to values in the control group. The data suggest that impaired insulin stimulation of in vivo glucose turn-over and muscle glycogen synthase activity tend to be restored during successful diet treatment of patients with Type 2 diabetes.

Key words: Insulin resistance, Type 2 (non-insulin-dependent) diabetes mellitus, hyperinsulinaemic clamp, indirect calorimetry, forearm glucose uptake, muscle, glycogen synthase, insulin receptor kinase.
Insulin resistant glucose metabolism plays a pathogenic role in the development of Type 2 (non-insulin-dependent) diabetes mellitus. However, insulin resistance is not a sufficient pathogenic factor since a concomitant reduction (acquired or inherited) in the secretory capacity of the pancreatic Beta cells is also pivotal for the development of diabetes [1].

Insulin resistance of glucose metabolism may have both primary (genetic) and secondary (metabolic) components, the latter being reversible. Thus, reduction of insulin resistance in Type 2 diabetes may be a rational therapeutic intervention to force the malady back into its subclinical state. In Type 2 diabetic patients the insulin resistance often improves during treatment with low-calorie diets $[2,3]$, whereas overfeeding of lean non-diabetic subjects may have opposite effects [4]. This occurrence may be attributable both to changes of energy intake perse and to changes in body weight or body composition.

In fat cells from patients with Type 2 diabetes dietary control of hyperglycaemia has been shown to improve glucose metabolism and insulin receptor kinase activity [3, 5]. However, skeletal muscle plays a dominant role in insulin-stimulated glucose disposal [6]. Glycogen synthesis in muscle accounts for a major portion of glucose disposal during hyperinsulinaemia [7]. Moreover, insulin resistance in non-diabetic subjects has been associated with reduced insulin effects on muscle glycogen synthase (GS) [8].

We have previously shown in newly-diagnosed Type 2 diabetic patients that treatment with sulfonylurea was associated with improved insulin sensitivity of glucose metabolism in peripheral tissue and a concomitant potentiated 
Table 1. Characteristics of Type 2 (non-insulin-dependent) diabetic patients and control subjects

\begin{tabular}{lccc}
\hline & $\begin{array}{c}\text { Control } \\
\text { subjects }\end{array}$ & \multicolumn{2}{l}{ Type 2 diabetic patients: } \\
\cline { 3 - 4 } & & & \\
\cline { 3 - 4 } & & Before diet & After diet \\
\hline$n$ (female/male) & $2 / 5$ & $2 / 5$ & - \\
Age (years) & $49 \pm 1$ & $51 \pm 5$ & - \\
Body weight $(\mathrm{kg})$ & $78.1 \pm 5.2$ & $97.7 \pm 4.6$ & $91.5 \pm 4.8$ \\
Body mass index $\left(\mathrm{kg} \cdot \mathrm{m}^{-2}\right)$ & $27.3 \pm 1.0$ & $31.3 \pm 1.4^{\mathrm{a}}$ & $29.3 \pm 1.2$ \\
s-Fructosamine $(\mu \mathrm{mol} / \mathrm{l})$ & $243 \pm 7$ & $441 \pm 43^{\mathrm{a}}$ & $301 \pm 18^{\mathrm{b}}$ \\
\hline
\end{tabular}

${ }^{\mathrm{a}} p<0.01$ vs control subjects; ${ }^{\mathrm{b}} p<0.01$ vs before diet

insulin activation of muscle GS [9]. The present study in newly-diagnosed Type 2 diabetic patients was carried out to study in vivo glucose metabolism and muscle enzymes with key functions in insulin-controlled glucose metabolism of skeletal muscle, i.e. GS activities, GS conversion rates (i.e. the rate of activation of endogenous GS by endogenous phosphatases), and insulin receptor binding and receptor kinase activity before and after improvement of glycaemic control with hypoenergetic dieting. Data from matched non-diabetic control subjects were included for comparison.

\section{Subjects and methods}

\section{Materials}

Monoiodinated Tyr- $\mathrm{A}_{14}-\left[{ }^{125} \mathrm{I}\right]$-insulin and native porcine insulin were generously donated by Novo-Nordisk Research Institute (Copenhagen, Denmark). Somatostatin was from Ferring AB (Malmö, Sweden). Uridine diphosphate-[U- $\left.{ }^{14} \mathrm{C}\right]$-glucose, adenosine $5^{\prime}-[\gamma$ ${ }^{32} \mathrm{P}$-triphosphate, and $\left[3-{ }^{3} \mathrm{H}\right]$-glucose were from New England Nuclear (Boston, Mass., USA). Sepharose-coupled wheat germ agglutinin (WGA) was from Pharmacia (Uppsala, Sweden). All other reagents and chemicals were from Sigma (St. Louis, Mo., USA).

\section{Study design}

Nine patients with newly-diagnosed Type 2 diabetes [10] entered the study and were examined at presentation. Patients who responded adequately to 6 weeks of diet treatment, i. e. with a fall in fasting plasma glucose level of more than $4 \mathrm{mmol} / \mathrm{l}$ or a post-diet fasting plasma glucose level of less than $7.5 \mathrm{mmol} / \mathrm{l}$ were re-examined under conditions similar to the pre-diet examination. Patients who failed to respond sufficiently to diet treatment were excluded from the study and treatment with oral antihyperglycaemic agents was started. For comparison seven healthy non-diabetic subjects with no family history of diabetes or essential hypertension underwent similar examinations. The control subjects were matched for age, whereas their mean body mass index was slightly lower than the mean post-diet body mass index in the diabetic group (Table 1). The study protocol was approved by the ethical committee of the county of Aarhus. Informed consent was obtained from all study participants according to the second Declaration of Helsinki.

\section{Diet composition}

Information on diet composition was obtained by a personal interview using a diet history method. All interviews were conducted by a trained dietician applying a structured interview form. Breakfast, lunch, and snacks were recorded on a weekly basis and dinner on a bi-weekly basis during the periods of intervention. Food models and photographs were used for estimating portion sizes [11]. Nutritional intake was calculated using a computer program based on Danish food composition tables. At the time of diagnosis information on habitual diets was obtained. After the initial examinations patients were prescribed an individual diabetes diet with an energy content of $5000-6000 \mathrm{~kJ}$ per day. Follow-up interviews and recordings were performed at the time of the second examination.

\section{Examinations}

Each examination lasted 2 days. On day 1 the study participants were examined with a $75 \mathrm{~g}$ oral glucose tolerance test (OGTT). On day 2 a euglycaemic clamp study was performed. The clamp experiments commenced at 08.00 hours. A teflon catheter was inserted into an antecubital vein for the administration of infusates (insulin, glucose, and $3-{ }^{3} \mathrm{H}$-glucose). In the contralateral extremity two catheters were inserted as follows: one catheter was introduced into a wrist vein of the hand which was kept in a heated box for sampling of arterialized blood and another catheter was inserted retrogradely into a deep antecubital vein draining forearm muscles for sampling of deep venous blood. Forearm blood flow per liter total forearm volume was determined with venous occlusion plethysmography using a strain gauge technique [12]. Forearm glucose uptake was calculated by multiplying total forearm blood flow and forearm arteriovenous glucose differences.

The experiments consisted of a 'basal period' of 150 min duration. Subsequently a continuous insulin infusion of $2.0 \mathrm{mU} \cdot \mathrm{kg}^{-1}$. $\mathrm{min}^{-1}$ was given during the next $180 \mathrm{~min}$. Throughout the clamp 3 ${ }^{3} \mathrm{H}$-glucose was infused continuously $(0.30 \mu \mathrm{Ci} / \mathrm{min})$ after a priming dose of $\mathrm{FPG} / 5 \times 30 \mu \mathrm{Ci}$ (maximum $60 \mu \mathrm{Ci}$ ) where $\mathrm{FPG}$ is the fasting plasma glucose level in $\mathrm{mmol} / \mathrm{l}$. Batches of $\left[3{ }^{3} \mathrm{H}\right]$-glucose contained no radiochemical contaminants as assessed by HPLC. Plasma glucose was determined by a glucose analyser (Beckman Instruments, Palo Alto, Calif. USA) at 10-min intervals during the clamp study and euglycaemia $(5.0 \mathrm{mmol} / \mathrm{l})$ was maintained by a variable glucose infusion. Rates of glucose disappearance were estimated according to the non-steady-state equations of DeBodo et al. [13] from blood sampling every $10 \mathrm{~min}$ during the final $30 \mathrm{~min}$ of each period.

\section{Indirect calorimetry}

Indirect calorimetric measurements with a ventilated hood system (Deltatrac Metabolic Monitor; Datex, Helsinki, Finland) were performed for $20 \mathrm{~min}$ at the end of the basal period and again at the end of the hyperinsulinaemic period. In calculating non-protein gaseous exchange, the exchange attributable to protein oxidation was subtracted from total gaseous exchange under the assumption that for each $g$ nitrogen excreted in urine 5.95 litres of $\mathrm{O}_{2}$ were consumed and 4.968 litres of $\mathrm{CO}_{2}$ were produced [14]. To determine total nitrogen excretion it was assumed that $90 \%$ of the nitrogen appeared in urea [14]. The proportion of non-protein energy derived from fat and carbohydrate oxidation was calculated from the non-protein respiratory quotient as described by Elia et al. [14].

\section{Muscle biopsies}

Using a Bergström biopsy needle muscle biopsies were obtained from the vastus lateralis muscle $20 \mathrm{~min}$ before termination of the basal period and again $20 \mathrm{~min}$ before termination of the hyperinsulinaemic period. Under local anaesthesia ( $1 \%$ lidocaine) a small incision was made through the skin and muscle sheath 15 $20 \mathrm{~cm}$ above the knee corresponding to the vastus lateralis muscle. The biopsy needle was inserted and a total amount of $200-250 \mathrm{mg}$ muscle was aspirated. The biopsies were cleaned of blood and fat droplets (within 15s) and immediately deep frozen in liquid ni- 
Table 2. Composition of diet

\begin{tabular}{lccc}
\hline & $\begin{array}{l}\text { Before } \\
\text { instruction }\end{array}$ & $\begin{array}{l}\text { After } \\
\text { instruction }\end{array}$ & $p$ value \\
\hline Total energy intake (kJ) & $11642 \pm 1724$ & $6811 \pm 746$ & $<0.03$ \\
Composition (\% of energy) & & & \\
Fat & $38 \pm 3$ & $26 \pm 1$ & $<0.03$ \\
Protein & $14 \pm 1$ & $21 \pm 1$ & $<0.03$ \\
Carbohydrates & $39 \pm 3$ & $47 \pm 2$ & $<0.03$ \\
Alcohol & $10 \pm 4$ & $6 \pm 3$ & NS \\
\hline
\end{tabular}

Table 3. Plasma glucose, insulin, and forearm glucose uptake during clamp experiment

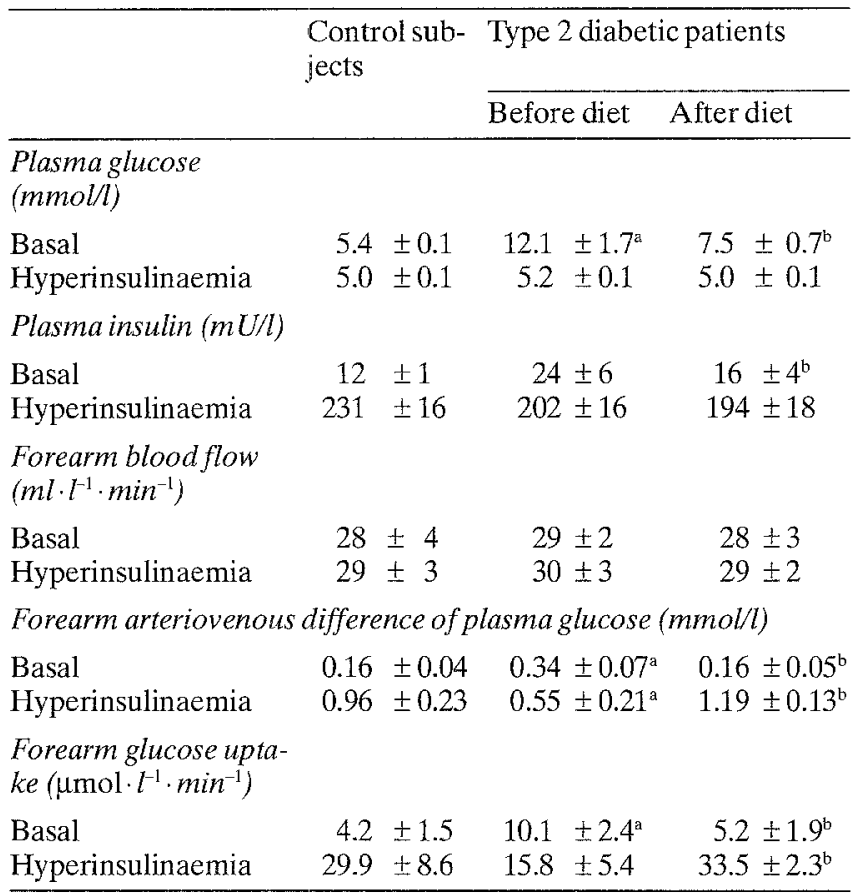

${ }^{a} \mathrm{p}<0.05$ vs control subjects; ${ }^{b} \mathrm{p}<0.05$ vs before diet

trogen. Muscle samples were stored at $-80^{\circ} \mathrm{C}$ until the biochemical analyses were performed.

\section{Muscle enzymes}

All four biopsies from the same subject were examined on the same day to avoid any influence of day-to-day variations in the assays. Muscle biopsies were homogenized on ice [15] and solubilization of the insulin receptors and subsequent partial purification on WGA sepharose columns were performed in the presence of $1 \mathrm{mmol} / \mathrm{l}$ vanadate to inhibit tyrosine phosphatase activity, otherwise as previously described [16]. Insulin binding to WGA-purified receptors was measured with polyethyleneglycol precipitation after incubation for $20 \mathrm{~h}$ at $15^{\circ} \mathrm{C}$ [16]. The number of insulin binding sites in the eluate was calculated from Scatchard analysis of binding data using the LIGAND computer program of Munson and Rodbard [17]. It was assumed that the curvilinearity of the plots was attributable to a non-specific insulin binding component which was handled as a computer-fitted parameter [16]. Insulin binding data were expressed per $100 \mathrm{mg}$ muscle. The kinase activities of the WGA-purified insulin receptors were measured at room temperature $\left(21^{\circ} \mathrm{C}\right)$ in the presence of $1 \mathrm{mmol} / 1$ vanadate after incubation of the receptors with $0,0.1,1$, 10 , and $100 \mathrm{nmol} / \mathrm{l}$ insulin for $60 \mathrm{~min}$ and with the artificial substrate poly(Glu-Tyr(4:1)) for another $30 \mathrm{~min}$. Phosphorylation with $\left[\gamma^{32} \mathrm{P}\right]-\mathrm{ATP}$ was performed for $60 \mathrm{~min}$ at $21^{\circ} \mathrm{C}$ [16]. Insulin receptor kinase activity was adjusted to the number of insulin binding sites in the eluate.

GS activity was measured as described earlier [15] using (final concentrations) $0.13 \mathrm{mmol} / \mathrm{l}$ uridine-diphosphate-[U- $\left.{ }^{14} \mathrm{C}\right]$-glucose, $0.67 \%$ (weight/volume) glycogen, and variable concentrations $(0$, $0.02,0.07,0.20,0.67,1.33,3.33,6.67 \mathrm{mmol} / \mathrm{l})$ of glucose 6 -phosphate (G6P). In the text one unit of GS activity equals the incorporation of one nmol of uridine-diphosphate-glucose into glycogen per min. Total activity of the GS activity is defined as the activity in the presence of a saturating concentration $(6.67 \mathrm{mmol} / \mathrm{l})$ of G6P. Fractional velocities were calculated for each $\mathrm{G} 6 \mathrm{P}$ concentration as the percentage of total activity [9]. The concentration of $\mathrm{G} 6 \mathrm{P}$ giving halfmaximal activity of glycogen synthesis $\left(A_{0.5}\right.$ for $\left.G 6 P\right)$ was calculated using a Hill-plot [18]. In ten segments from the same muscle biopsy the inter-assay coefficients of variation were 0.12 for $A_{0.5}$ and 0.13 for total GS activity.

To assess endogenous phosphatase activity the rate of activation of the endogenous GS, i. e. the rate of conversion of the endogenous GS from the G6P-dependent form to the G6P-independent form was measured as previously described [19] under conditions where the phosphatase inhibitor fluoride was left out from the buffers. Briefly, the muscle biopsy was homogenized in an ice-cooled buffer ( $230 \mu \mathrm{l}$ buffer $/ 10 \mathrm{mg}$ muscle) containing $50 \mathrm{mmol} / \mathrm{l}$ Tris(hydroxymethyl)aminometahane- $\mathrm{HCl}$ (Tris- $\mathrm{HCl}$ ), $10 \mathrm{mmol} / \mathrm{l}$ ethylenediaminetetraacetic acid (EDTA), and $50 \mathrm{mmol} / \mathrm{l}$ mercaptoethanol, $\mathrm{pH}$ 7.8. The homogenate was centrifuged at $6000 \mathrm{~g}$ for $20 \mathrm{~min}$ at $4^{\circ} \mathrm{C}$. From the supernatant $100 \mu \mathrm{l}$ was diluted with $75 \mu \mathrm{l}$ buffer and then incubated at $30^{\circ} \mathrm{C}$. The activation reaction was terminated at $0,5,10$, 15 and 30 min by diluting $26 \mu \mathrm{l}$ of the mixture in $975 \mu \mathrm{l}$ of an ice-cold buffer containing $50 \mathrm{mmol} / 1$ Tris- $\mathrm{HCl}, 20 \mathrm{mmol} / \mathrm{l}$ EDTA, and $130 \mathrm{mmol} / 1 \mathrm{NaF}, \mathrm{pH}$ 7.8. GS activity was measured in the absence and in the presence of $6.7 \mathrm{mmol} / 1 \mathrm{G} 6 \mathrm{P}$ as described above. The rate of conversion of GS was expressed as units of G6P independent form (I-form) of GS produced per min per mg protein. Protein in enzyme extracts was measured according to Bradford et al. [20].

\section{Chemical quantities}

Plasma glucose was analysed with a glucose oxidase method (glucose analyser, Beckman Instruments). Plasma insulin and C-petide concentrations were measured radioimmunologically (radioimmunoassay kits, Novo-Nordisk). Plasma non-esterified fatty acids (NEFA) were determined colorimetrically with a commercial kit (Wako Chemicals, Osaka, Japan). Fructosamine in serum was determined photometrically [21].

\section{Statistical analysis}

Data are expressed as means $\pm S E M$. Differences within groups before and after diet treatment were tested for statistical significance with the Wilcoxon matched-pairs test. Differences between groups were tested with the Mann-Whitney test. Correlations were analysed with linear regression statistics. $p$ values less than 0.05 were considered statistically significant.

\section{Results}

All seven patients who improved in glycaemic control during diet therapy were re-studied approximately 6 weeks after the primary study. The change in diet composition before and after diet instructions is given in Table 2. Improvements of plasma glucose levels during OGTT and of plasma fructosamine concentrations are shown in Figure 1 and Table 1, respectively. Plasma fruc- 

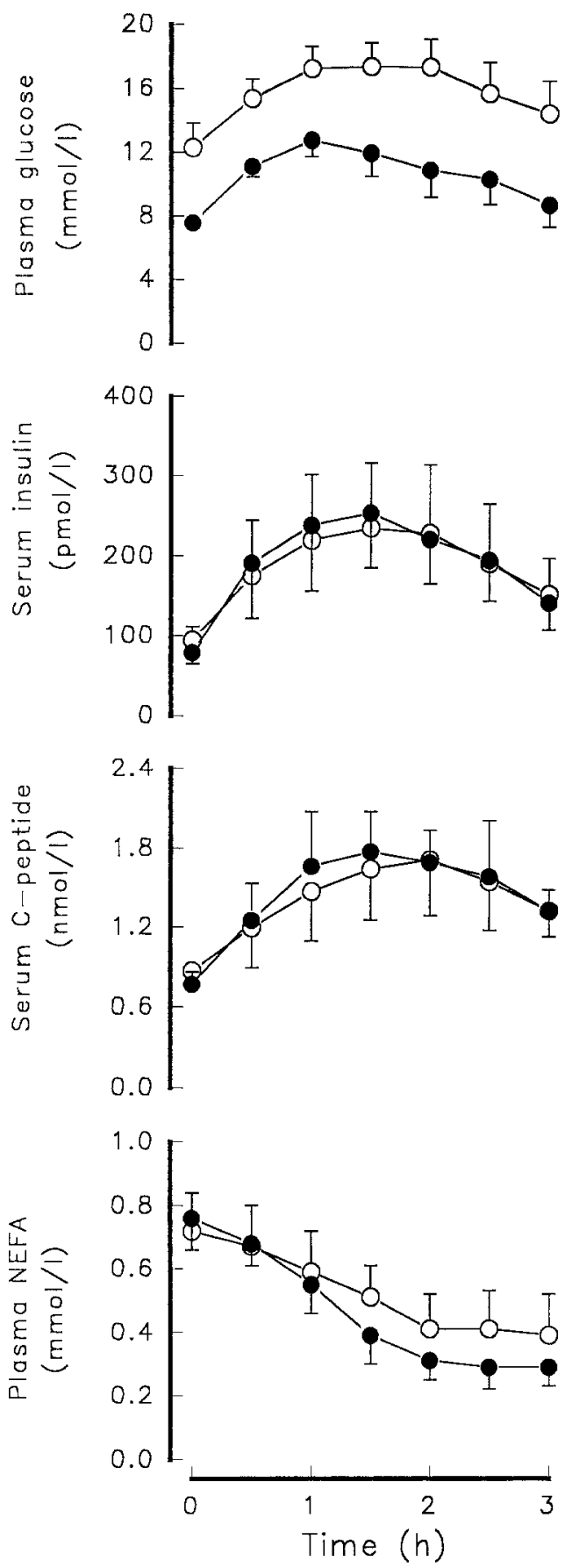

Fig. 1. Plasma glucose, serum insulin, serum C-peptide, and plasma non-esterified fatty acids (NEFA) during oral glucose tolerance tests in seven newly-diagnosed obese Type 2 diabetic patients before $(O)$ and after ( $)$ dietary control of hyperglycaemia. Mean values and SEM are shown

tosamine rather than $\mathrm{HbA}_{1 c}$ was employed to estimate average glycaemic control during previous weeks due to the short duration of the study. Plasma insulin levels in the basal (post-absorptive) state were slightly lower after diet (Table 3, $p=0.05$ ). Despite pronounced improvement of glycaemic control, excursions of mean plasma insulin concentrations and mean plasma $C$-peptide concentrations during OGTT were similar before and after diet intervention (Fig. 1). Also, mean plasma NEFA levels in the basal state and their decline during OGTT were comparable after diet-induced amelioration of hyperglycaemia (Fig. 1).

During the hyperinsulinaemic step of the clamp experiment plasma insulin levels in diabetic patients were similar before and after diet intervention and also comparable to plasma insulin levels in control subjects (Table 3). Before diet treatment insulin-mediated glucose metabolism and non-oxidative glucose metabolism were significantly $(p<0.05)$ reduced compared to control subjects (Fig. 2). After diet therapy insulin-mediated glucose disposal increased significantly in Type 2 diabetic patients and the major portion of this change was accounted for by an increase in non-oxidative glucose metabolism to levels not significantly different from those in control subjects (Fig.2). Diet therapy had no significant effect on insulinstimulated oxidative glucose metabolism ( $36 \pm 11$ vs $46 \pm 5 \mathrm{mg} \cdot \mathrm{m}^{-2} \cdot \mathrm{min}^{-1}, p=\mathrm{NS}$ ). The basal state forearm glucose uptake rates decreased after diet therapy of diabetic patients to levels comparable to those in control subjects (Table 3). During hyperinsulinaemia forearm glucose uptake became normal after diet treatment (Table 3). The post-diet increase in net glucose turnover during hyperinsulinaemia correlated significantly with both the fall in fasting plasma glucose level, the fall in plasma fructosamine level, and with weight loss (Fig. 3). In contrast, there was no correlation between the change in total caloric intake and the change in net glucose turnover (Fig.3).

In Type 2 diabetic patients the recovery of insulin receptors (i.e. maximal insulin binding as calculated from scatchard plots, Fig. 4) was $91 \pm 8 \mathrm{fmol} / 100 \mathrm{mg}$ muscle before diet vs $86 \pm 21 \mathrm{fmol} / 100 \mathrm{mg}$ muscle after diet ( $p=\mathrm{NS}$ ). Maximal insulin binding tended to be higher in control subjects $(109 \pm 7 \mathrm{fmol}$ receptors $/ 100 \mathrm{mg}$ muscle; Fig. 4), but the difference did not reach statistical significance. Basal and insulin-stimulated receptor kinase activities were unaffected by diet-induced improvement of glycaemic control (Fig.4) and the insulin receptor kinase activities were not significantly different from values in the control group (Fig.4). In the post-clamp biopsies insulin receptor binding and kinase activities were similar (data not shown).

Total GS activity (measured with saturating concentrations of G6P and physiological concentrations of uridinediphosphate glucose) was unaltered after diet treatment and was comparable to values obtained in the control group (Fig. 5). In all subjects total GS activity remained stable during the clamp experiment (Fig.5). In the basal state the half-maximal activation constant for G6P $\left(\mathrm{A}_{0.5}\right)$ was comparable in all groups and insulin stimulation caused a significant $(p<0.03)$ reduction in $\mathrm{A}_{0.5}$ in all groups (Fig.5). However, during hyperinsulinaemia the lowering of $\mathrm{A}_{0.5}$ was more pronounced after diet therapy of Type 2 diabetic patients $(0.43 \pm 0.06 \mathrm{mmol} / \mathrm{l}$ before diet treatment vs $0.30 \pm 0.04 \mathrm{mmol} / 1$ after diet treatment; $p<0.03$; control subjects: $0.22 \pm 0.03 \mathrm{mmol} / 1$ ). Thus, whereas GS activation by insulin was significantly $(p<0.03)$ reduced in untreated Type 2 diabetic patients as compared to control subjects, this difference became nonsignificant after dietary treatment (Fig. 5). There was a 


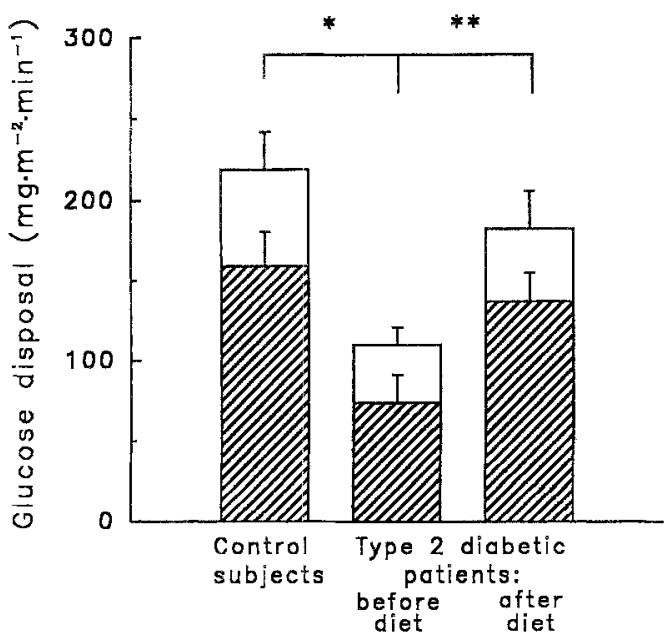

Fig. 2. Insulin-mediated glucose disposal during the hyperinsulinaemic step of the clamp in seven control subjects and seven newlydiagnosed obese Type 2 diabetic patients before and after diet-induced amelioration of glycaemic control. The contribution from non-oxidative glucose metabolism is shown as hatched bars. Mean values and SEM are shown. ${ }^{*} p<0.03, * * p<0.05$

large variation in the rate of conversion of GS to more active forms (through interactions with phosphatases) and no significant difference was demonstrated in mean values of GS conversion rate between Type 2 diabetic patients and healthy control subjects (Fig.5). Diet-induced normalization of glycaemic control was not accompanied by significant changes in GS conversion rate (Fig.5).

\section{Discussion}

Prescription of a low-calorie diet is a rational first-choice treatment for Type 2 diabetes, since it may enhance insulin sensitivity. As previously reported [2] improvement of OGTT during diet treatment was associated with a slight reduction in fasting serum insulin levels whereas serum insulin excursions during OGTT were comparable to pre-diet values. Indeed, mean plasma insulin levels during OGTT increased after diet in some subjects whereas it decreased in others. According to the so-called 'Starling curve for insulin secretion' insulin secretion is stimulated with increasing glycaemia until reaching a 'turning point'. Thereafter it is inversely associated with increased hyperglycaemia [22]. In the present study the insulin secretion of some patients may have been on the upward slope of this curve and in others it may have been on the downward slope. This would explain the inconsistency of changes in insulinaemia. Plasma NEFA levels during OGTT were not significantly changed after diet treatment and consequently not likely to be implicated in the amelioration of insulin resistance in this study.

In Type 2 diabetic patients both oxidative and non-oxidative glucose metabolism are impaired during hyperinsulinaemia [23, 24]. However, non-oxidative glucose metabolism is quantitatively dominant under hyperinsulinaemic clamp conditions [24]. A reduced insulin resistance to glucose metabolism after diet treatment is well known from previous studies $[2,3]$. In the present report the increase in insulin-stimulated glucose disposal after diet treatment was primarily accounted for by an enhanced non-oxidative glucose turn-over. Our finding of slightly lower basal insulinaemia after diet treatment is probably not essential to the observed changes in in vivo insulin action. Indeed, when Type 2 diabetic patients are treated with insulin or sulfonylurea there is a concomitant increase in diurnal hyperinsulinaemia which does not obstruct an increase in insulin sensitivity $[9,25,26]$. Thus, although hyperinsulinaemia may cause insulin resistance in non-diabetic subjects $[27,28]$ improved metabolic control in Type 2 diabetes seems to have a greater impact on the insulin sensitivity than the potential negative effects of hyperinsulinaemia.

Our forearm balance data confirm previous findings [29] that hyperglycaemia in the basal (post-absorptive)

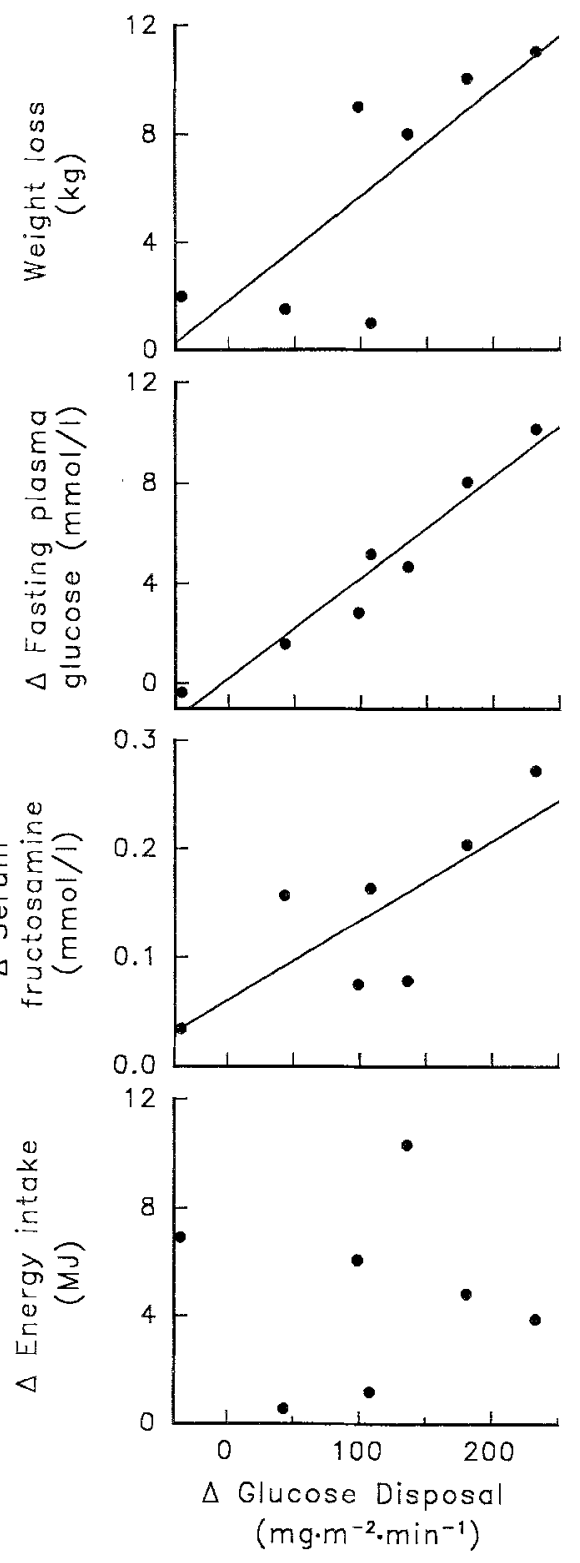

Fig. 3. Correlation of the diet-induced change of insulin-mediated glucose disposal during hyperinsulinaemia with weight loss $(r=0.78$, $p<0.05)$, reduction in fasting plasma glucose level $(r=0.97$, $p<0.001)$, reduction in plasma fructosamine concentration $(r=0.77$, $p<0.05)$ and reduction in dietary energy intake $(r=0.02, p=\mathrm{NS})$ 


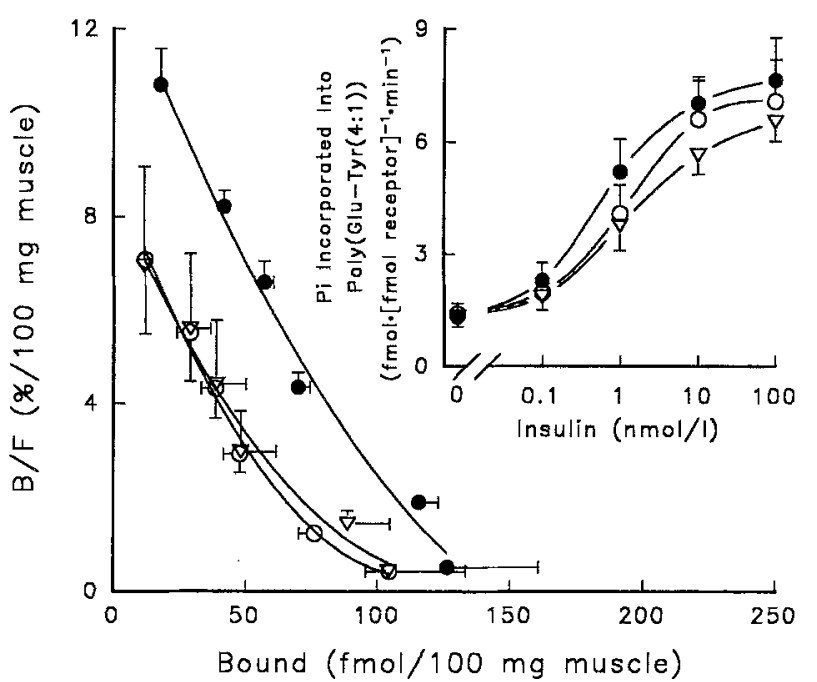

Fig. 4. Scatchard plots of insulin receptor binding to wheat germ agglutinin-purified insulin receptors extracted from skeletal muscle of control subjects ( $)$, Type 2 diabetic patients before diet $(O)$ and after diet $(\nabla)$. Insert: Basal and insulin-stimulated kinase activity of insulin receptors (given as the rate of phosphorylation of poly(Glu$\operatorname{Tyr}(4: 1))$ from the same groups. Mean values and SEM are shown

state causes an increased glucose uptake in forearm muscle due to 'non-insulin-mediated glucose uptake' which is normal in Type 2 diabetes [30]. Consequently, lower basal plasma glucose levels during diet treatment lead to a normalization of basal forearm glucose uptake. Insulin-stimulated glucose uptake in forearm muscle also tended to normalize after diet treatment. Such data emphasise the importance of skeletal muscle for the observed enhancement of peripheral insulin sensitivity during diet treatment.

Although few patients were studied the finding of a correlation between weight loss and increase in insulinstimulated glucose turn-over suggests that weight loss per se may be important for diabetic control. Since we found no correlation between reduction in energy intake and increase in insulin-stimulated glucose utilization it may be speculated that reduction of insulin resistance is not solely a question of diminished caloric intake. However, the present results do not justify extensive conclusions on this subject.

Near-normalization of glycaemic control during diet treatment in obese patients with Type 2 diabetes caused no change in insulin receptor binding or kinase activity which were not significantly different from values in the control group. The latter confirms previous findings in studies of insulin receptors from obese Type 2 diabetic patients vs obese control subjects [31,32]. Similarly, treatment of Type 2 diabetic patients with sulfonylurea caused no change in muscle insulin receptor function [9]. By contrast, insulin receptor kinase activity from adipocytes may improve after diet treatment and weight reduction in Type 2 diabetic patients [3].

It is in accordance with several other studies that the estimate of total GS activity in muscle (measured at saturating G6P concentrations) was similar in Type 2 diabetic patients and control subjects. It is not surprising therefore, that total GS activity did not change during diet-induced improvement of glycaemic control as already demonstrated by Johnson et al. [33]. This also parallels findings after sulfonylurea treatment of Type 2 diabetic patients [9]. Also in line with previous studies [33-35] is our finding that the activity indices for GS ( $A_{0.5}$ for G6P) in the basal state were similar in control subjects and diabetic patients (both before and after diet treatment). To further characterize the GS enzyme we wanted to study the rate with which it became activated due to interference with the endogenous phosphatases [36]. The present finding that GS conversion rates did not change after improved glycaemic control in diabetic patients might suggest that phosphatase activity is less dependent on the metabolic state than is GS activity. Kida et al. [37] found in muscle biopsies obtained in the basal state that the activity index for GS was normal whereas the GS-phosphatase activity was decreased. We saw a similar tendency, although statistical significance was not reached. However, since the GS is probably phosphorylated differently during hyperinsulinaemia before and after diet treatment there is a possibility that differences in conversion rates might not be comparable. To circumvent this problem other groups have added exogenous GS [37]. However, such assay preparations still contain considerable amounts of endogenous GS which interferes with measurements (Bak, J.F. unpub-
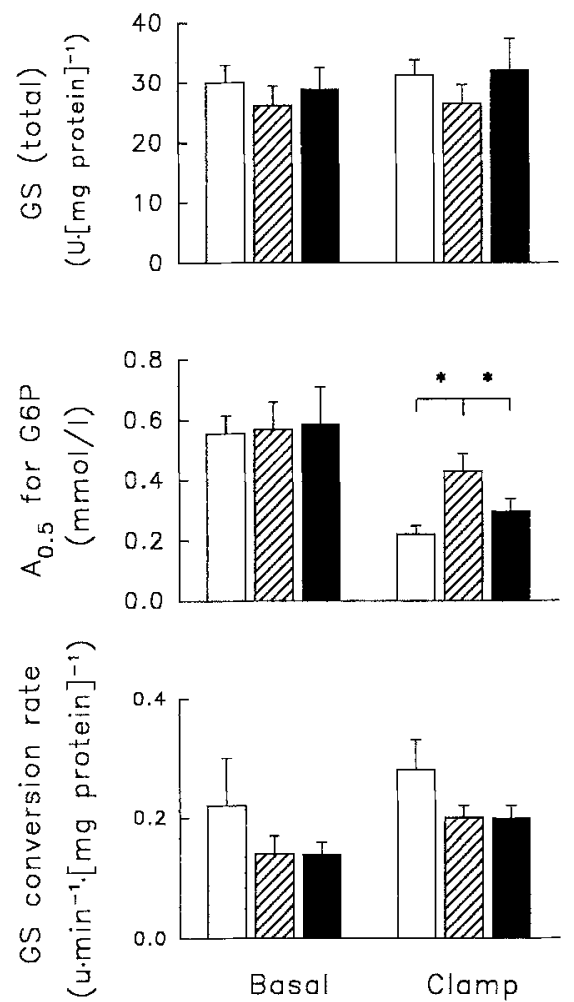

Fig.5. Glycogen synthase activity in skeletal muscle biopsics obtained in the basal state and during hyperinsulinaemic, euglycaemic clamp given as: (from upper to lower) total glycogen synthase (GS) activity, half-maximal activation constant for glucose 6-phosphate ( $A_{05}$ for $G 6 P$ ), and conversion rate of $G S$ i.e. the rate of accumulation of G6P independent from (I form) during $10 \mathrm{~min}$ of incubation in the absence of fluoride. Data are from seven obese control subjects ( $\square$ ), seven obese Type 2 diabetic patients before diet treatment $\left(D_{A}\right)$ and after diet treatment ( $)$. Mean values \pm SEM are shown; $* p<0.03$ 
lished results). More precise estimation of GS phosphatase activity must await development of more appropriate techniques.

Insulin exposure conveys a stimulation of muscle GS through dephosphorylations which lead to a decrease in $\mathrm{A}_{0.5}$ for G6P. It is well known that insulin resistance in normoglycaemic subjects is associated with insulin resistant activation of GS [8]. In the present study insulin activation of GS in Type 2 diabetic patients improved after nonpharmacological (dietary) treatment. Sulfonylurea treatment of untreated Type 2 diabetic patients (non-responders to dietary intervention) had similar effects [9].

According to the protocol, the basal step of the clamp was more hyperglycaemic in Type 2 diabetic patients before than after diet. The importance of hyperglycaemia for overall insulin sensitivity and insulin activation of muscle GS has attracted much interest in recent years. It appears that acute elevations of plasma glucose do not interfere with insulin activation of muscle GS in normoglycaemic healthy control subjects $[36,38]$ whereas chronic hyperglycaemia in diabetic patients may be important for insulin stimulation of GS $[34,35,39]$. Thus, over-night normalization of plasma glucose (through a low-dose insulin infusion) in Type 2 diabetic patients caused an inactivation of GS both in the basal state and during insulin stimulation [34]. Some years ago it was demonstrated that catecholamines may be released in variable amounts in response to an acute fall in plasma glucose from hyperglycaemia to euglycaemia in diabetic subjects $[40,41]$. However, there was no proportionality between the fall in plasma glucose and catecholamine release and the findings were not confirmed in a more recent report [23].

Our finding that caloric intake may influence insulinstimulated glucose disposal and muscle GS activation is in accordance with findings in normoglycaemic healthy volunteers [4]. However, in contrast to the present study Johnson et al. [33] have reported an absence of insulin activation of GS in muscle from Type 2 diabetic subjects both before and after dietary control of hyperglycaemia. One explanation for this discrepancy may be that we use $A_{0.5}$ for G6P based on several measurements of fractional velocities as an estimate of GS activity. Fractional velocities have been reported to be more sensitive than activity ratios (absence of $\mathrm{G} 6 \mathrm{P} /$ presence of $10 \mathrm{mmol} / \mathrm{l} \mathrm{G} 6 \mathrm{P}$ ) for determination of changes in GS activity [42]. Furthermore, we only re-studied a selected group of Type 2 diabetic patients who responded to diet therapy.

Newly-diagnosed patients with Type 2 diabetes who respond to non-pharmacological treatment may be in the same metabolic state as before the development of clinical diabetes. Recent reports from first-degree relatives of patients with Type 2 diabetes suggest that impaired insulin stimulation of glucose storage [43] and reduced insulin stimulation of GS activity in muscle [44] may be primary defects in this disease. However, the present data suggest that defects in insulin action may be reversible during nonpharmacological treatment and that diet habits may be of a primary importance as well. To address this crucial question the effects of diet intervention in non-diabetic firstdegree relatives to Type 2 diabetic patients should be examined.
In conclusion, newly-diagnosed obese Type 2 diabetic patients showed an impaired insulin stimulation of glucose disposal, non-oxidative glucose metabolism, and forearm glucose uptake. In muscle biopsies an abnormally low insulin activation of GS was found whereas there were no defects in insulin receptor kinase activities. Diet-induced improvement of glycaemic control tended to normalize the defects, without changing the rate by which GS converts to more active forms.

Acknowledgements. We thank Ms. A. Mengel and Ms. L. Blak for excellent technical assistance. Furthermore we are indebted to M.Lauritsen for measurements of plasma levels of non-esterified fatty acids, C-peptide, and insulin. The study was supported by grants from the Danish Medical Research Council, Danish Diabetes Association, Aarhus Universitets Forskningsfond, Novos Fond, and Nordisk Insulin Fond.

\section{References}

1. Turner RC, Matthews DR, Clark A, O'Rahilly S, Rudenski AS, Levy J (1988) Pathogenesis of NIDDM - a disease of deficient insulin secretion. Baillieres Clin Endocrinol Metab 2: 327-342

2. Henry RR, Wallace P, Olefsky JM (1986) Effects of weight loss on mechanisms of hyperglycemia in obese non-insulin-dependent diabetes mellitus. Diabetes 35:990-998

3. Freidenberg GR, Reichart DR, Olefsky JM, Henry RR (1988) Reversibility of defective adipocyte insulin receptor kinase activity in non-insulin-dependent diabetes mellitus. Effect of weight loss. J Clin Invest 82: 1398-1406

4. Mott D, Lillioja S, Bogardus C (1986) Overnutrition induced decrease in insulin action for glucose storage: in vivo and in vitro in man. Metabolism 35: 160-165

5. Hjøllund E, Pedersen O, Sørensen NS (1987) Adipocyte insulin binding and action in moderately obese NIDDM patients after dietary control of plasma glucose: reversal of postbinding abnormalities. Diabetes Care 10: 306-312

6. Baron AD, Brechtel G, Wallace P, Edelman SV (1988) Rates and tissue sites of non-insulin- and insulin-mediated glucose uptake in humans. Am J Physiol 255: E769-E774

7. Shulman GI, Rothman DL, Jue T, Stein P, DeFronzo RA, Shulman RG (1990) Quantitation of muscle glycogen synthesis in normal subjects and subjects with non-insulin-dependent diabetes by ${ }^{13} \mathrm{C}$ nuclear magnetic resonance spectroscopy. $\mathrm{N}$ Engl J Med 322: 223-228

8. Young AA, Bogardus C, Wolfe-Lopez D, Mott DM (1988) Muscle glycogen synthesis and disposition of infused glucose in humans with reduced rates of insulin-mediated carbohydrate storage. Diabetes 37: 303-308

9. Bak JF, Schmitz O, Sørensen NS, Pedersen O (1989) Postreceptor effects of sulfonylurea on skeletal muscle glycogen synthase activity in type II diabetic patients. Diabetes 38 : 1343-1350

10. National diabetes data group (1979) Classification and diagnosis of diabetes mellitus and other categories of glucose intolerance. Diabetes 28: 1039-1057

11. Haraldsdottir J, Holm L, From V, Sass Nielsen L (1985) Estimation of portion sizes by means of food models. Naringsforskning 29: 59-65

12. Møller N, Butler PC, Antsiferov MA, Alberti KGMM (1989) Effects of growth hormone on insulin sensitivity and forearm metabolism in normal man. Diabetologia 32: 105-110

13. DeBodo R, Steele R, Altszuler N, Dunn A, Bishop J (1963) On the hormonal regulation of carbohydrate metabolism: studies with C14 glucose. Recent Prog Horm Res 19: 445-488

14. Elia M, Folmer P, Schlatmann A, Goren A, Austin S (1988) Carbohydrate, fat, and protein metabolism in muscle and in the whole body after mixed meal ingestion. Metabolism 37: 542-551 
15. Bak JF, Jacobsen UK, Jørgensen FS, Pedersen O (1989) Insulin receptor function and glycogen synthase activity in skeletal muscle biopsies from patients with insulin-dependent diabetes mellitus: effects of physical training. J Clin Endocrinol Metab 69: 158-164

16. Bak JF, Handberg A, Beck-Nielsen H, Pedersen O (1990) Kinetics of insulin binding and kinase activity of the partially purified insulin receptor from human skeletal muscle. Biochim Biophys Acta 1052: 306-312

17. Munson PJ, Rodbard D (1980) LIGAND: a versatile computerized approach for characterization of ligand-binding systems. Anal Biochem 107: 220-239

18. Kochan RG, Lamb DR, Lutz SA, Perrill CV, Reimann EM, Schlender KK (1979) Glycogen synthase activation in human skeletal muscle: effects of diet and exercise. Am J Physiol 236: E660-E666

19. Bak JF, Pedersen O (1990) Exercise-enhanced activation of glycogen synthase in human skeletal muscle. Am J Physiol 258: E957-E963

20. Bradford MM (1976) A rapid and sensitive method for the quantitation of microgram quantities of protein utilizing the principle of protein-dye binding. Anal Biochem 72: 248-254

21. Johnson RN, Metcalf PA, Baker JR (1982) Fructosamine: a new approach to the estimation of serum glycosyl protein. An index of diabetic control. Clin Chim Acta 127: 87-95

22. DeFronzo RA (1988) The triumvirate: $\beta$-cell, muscle, liver. A collusion responsible for NIDDM. Diabetes 37: 667-687

23. Golay A, DeFronzo RA, Ferrannini E et al. (1988) Oxidative and non-oxidative glucose metabolism in non-obese type 2 (noninsulin-dependent) diabetic patients. Diabetologia 31: 585-591

24. Groop LC, Bonadonna RC, DelPrato S et al. (1989) Glucose and free fatty acid metabolism in non-insulin-dependent diabetes mellitus. Evidence for multiple sites of insulin resistance. J Clin Invest 84:205-213

25. Garvey WT, Olefsky JM, Griffin J, Hamman RF, Kolterman OG (1985) The effect of insulin treatment on insulin secretion and insulin action in type II diabetes mellitus. Diabetes 34: 222-234

26. Baron AD, Laakso M, Brechtel G, Edelman SV (1991) Reduced capacity and affinity of skeletal muscle for insulin-mediated glucose uptake in noninsulin-dependent diabetic subjects. Effects of insulin therapy. J Clin Invest 87: 1186-1194

27. Rizza RA, Mandarino LJ, Genest J, Baker BA, Gerich JE (1985) Production of insulin resistance by hyperinsulinemia in man. Diabetologia 28: 70-75

28. Marangou AG, Weber KM, Boston RC et al. (1986) Metabolic consequences of prolonged hyperinsulinemia in humans. Evidence for induction of insulin insensitivity. Diabetes 35: 1383 1389

29. Firth RG, Bell PM, Marah HM, Hansen I, Rizza RA (1986) Postprandial hyperglycemia in patients with noninsulin-dependent diabetes mellitus. Role of hepatic and extrahepatic tissues. J Clin Invest 77:1525-1532

30. Baron AD, Kolterman OG, Bell JM, Mandarino LJ, Olefsky JM (1985) Rates of noninsulin-mediated glucose uptake are elevated in Type II diabetic subjects. J Clin Invest 76:1782-1788

31. Arner P, Pollare T, Lithell H, Livingston JN (1987) Defective insulin receptor tyrosine kinase in human skeletal muscle in obesity and type 2 (non-insulin-dependent) diabetes mellitus. Diabetologia 30: 437-440

32. Caro JF, Sinha MK, Raju SM et al. (1987) Insulin receptor kinase in human skeletal muscle from obese subjects with and without noninsulin dependent diabetes. J Clin Invest 79: 1330-1337
33. Johnson AB, Argyraki M, Thow JC, Broughton D, Jones IR, Taylor R (1990) Effects of intensive dietary treatment on insulinstimulated skeletal muscle glycogen synthase activation and insulin secretion in newly presenting type 2 diabetic patients. Diabetic Med 7: 420-428

34. Kelley DE, Mandarino LJ (1990) Hyperglycemia normalizes insulin-stimulated skeletal muscle glucose oxidation and storage in noninsulin-dependent diabetes mellitus. J Clin Invest 86: 1999 2007

35. Mandarino LJ, Consoli A, Kelley DE, Reilly JJ, Nurjhan N (1990) Fasting hyperglycemia normalizes oxidative and nonoxidative pathways of insulin-stimulated glucose metabolism in noninsulin-dependent diabetes mellitus. J Clin Endocrinol Metab 71: 1544-1551

36. Bak JF, Møller N, Schmitz O, Richter EA, Pedersen O (1991) Effects of hyperinsulinemia and hyperglycemia on insulin receptor function and glycogen synthase activation in skeletal muscle of normal man. Metabolism 40:830-835

37. Kida Y, Puente AE-D, Bogardus C, Mott D (1990) Insulin resistance is associated with reduced fasting and insulin-stimulated glycogen synthase phosphatase activity in human skeletal muscle. J Clin Invest 85: 476-481

38. Yki-Järvinen H, Mott D, Young AA, Stone K, Bogardus C (1987) Regulation of glycogen synthase and phosphorylase activities by glucose and insulin in human skeletal muscle. J Clin Invest $80: 95-100$

39. Devlin JT, Hirshman M, Horton ED, Horton ES (1987) Enhanced peripheral and splanchnic insulin sensitivity in NIDDM men after single bout of exercise. Diabetes 36: 434-439

40. DeFronzo RA, Hendler R, Christensen NJ (1980) Stimulation of counter-regulatory hormonal responses in diabetic man by a fall in glucose concentration. Diabetes 29: 125-131

41. Santiago JV, Clarke WL, Shah SD, Cryer PE (1980) Epinephrine, norepinephrine, glucagon, and growth hormone release in association with physiological decrements in the plasma glucose concentration in normal and diabetic man. J Clin Endocrinol Metab 51: 877-883

42. Guinovart JJ, Salavert A, Massagué J, Ciudad CJ, Salsas E, Itarte E (1979) Glycogen synthase: a new activity ratio assay expressing a high sensitivity to the phosphorylation state. FEBS Lett 106: 284-288

43. Eriksson J, Franssila-Kallunki A, Ekstrand A et al. (1989) Early metabolic defects in persons at increased risk for non-insulin-dependent diabetes mellitus. N Engl J Med 321:337-343

44. Vaag A, Henriksen JE, Beck-Nielsen H (1992) Decreased insulin activation of glycogen synthase in skeletal muscles in young nonobese caucasian first-degree relatives of patients with non-insulin-dependent diabetes mellitus. J Clin Invest 89: 782 788

Received: 24 February 1992

and in revised form: 21 April 1992

Dr. J.F. Bak

Medical-Endocrinological Department C

Aarhus Amtssygehus

DK-8000 Aarhus C

Denmark 